\title{
NULIDAD MATRIMONIAL INSTADA POR TERCERO Y COMPETENCIA INTERNACIONAL EN EL REGLAMENTO 2201/2003. COMENTARIO A LA STJUE DE 13 DE OCTUBRE DE 2016, ASUNTO C-294/15*
}

\author{
MARRIAGE ANNULMENT SUED BY THIRD PARTY AND \\ JURISDICTIONAL RULES IN EU REGULATION 2201/2003. \\ JUDGMENT OF THE COURT OF 13 OCTOBER 2016, CASE \\ C-294/15
}

\author{
Pilar Peiteado Mariscal \\ Profesora Titular de Derecho Procesal \\ Universidad Complutense de Madrid
}

Recibido: 15.01.2018 / Aceptado: 25.01.2018

DOI: https://doi.org/10.20318/cdt.2018.4141

\begin{abstract}
Resumen: Al hilo de la STJUE de 13 de octubre de 2016, este comentario examina el ámbito de aplicación y los foros de competencia del Reglamento 2201/2003, desde la perspectiva de los procesos de nulidad matrimonial instados por un tercero distinto de los cónyuges, y atiende también a la relación de esta norma con el resto de los Reglamentos que regulan el Derecho de familia en el ámbito europeo.

Palabras clave: Nulidad matrimonial, Reglamento 2201/2003, Derecho de familia europeo.

Abstract: Taking as frame of reference the Judgment of the EUC in Case C-294/15, this paper focuses on the scope and the jurisdiction rules in the EU Regulation 2201/2003. It tries to pay special atention to marriage annulment trials sued by a third party, and also to the relationship between EU Regulation 2201/2003 and the others EU regulations wich rule European Family Law.

Keywords: Marriage annulment, EU Regulation 2201/2003, European Family Law.

Sumario: I. Presentación. II. Supuesto de hecho. III. Breve contextualización. Transnacionalidad y derecho de familia y sucesiones.IV.Cuestiones prejudiciales relativas al ámbito de aplicación del reglamento 2201/2003. V. Cuestión prejudicial relativa al foro de competencia para conocer del proceso de nulidad instado por un tercero.
\end{abstract}

\section{Presentación}

1. La sentencia objeto de este comentario responde a tres cuestiones prejudiciales formuladas en un contexto no frecuente, el transcurso de un proceso de nulidad matrimonial. Como es sabido, el Reglamento 2201/2003 regula la competencia, el reconocimiento y la ejecución de resoluciones judiciales

\footnotetext{
* Este trabajo se encuadra dentro de los resultados del Proyecto de Investigación "La armonización del proceso civil en la Unión Europea" (DER 2015-64756-P), financiado por el MINECO. Y está dedicado a Carlos Martín Brañas, profesor de Derecho Procesal de la Universidad Complutense de Madrid.
} 
recaídas en procesos que versan, bien sobre cuestiones matrimoniales -separación, divorcio y nulidad-, bien sobre responsabilidad parental, bien relativos a la sustracción de menores. Estos tres ámbitos, tan relacionados en la realidad de las relaciones personales, tienen en el Reglamento un tratamiento diferenciado, con foros de competencia propios y específicos; y la práctica demuestra que son los asuntos de responsabilidad parental y sustracción de menores los que más cuestiones prejudiciales provocan. No son numerosos, pues, los pronunciamientos del TJUE sobre los foros de competencia en materia matrimonial, y no hay ninguno anterior a la Sentencia de 13 de octubre de $2016^{1}$ que se proyecte sobre un supuesto de hecho parecido o equivalente al que en ella se resuelve. La resolución comentada es trascendente, por tanto, a causa del ámbito sobre el que recae, pero también, como se verá, por la solución concreta que ofrece y los criterios interpretativos en los que se apoya.

\section{Supuesto de hecho}

2. La Sra. Mikolajczyk, en su condición de heredera de la Sra. Zdzislawa Czarnecka, que estuvo casada con el Sr. Czarnecki, insta ante un tribunal de Varsovia la nulidad del segundo matrimonio del mencionado Sr. Czarnecki, contraído en París con Marie Louise Czarnecka, alegando que al tiempo de estas nupcias subsistía todavía el vínculo matrimonial entre el Sr. Czarnecki y su causante, la Sra. Zdzislawa Czarnecka.

El Sr. Czarnecki había fallecido al tiempo de formularse la demanda, pero la Sra. Marie Louise Czarnecka se opuso a ella aduciendo la falta de competencia internacional de los tribunales polacos, puesto que tanto la última residencia de ambos cónyuges como la residencia actual de la demandada determinaban la competencia de los tribunales franceses al amparo de los guiones segundo o tercero del artículo 3.1 a) del Reglamento. El tribunal de instancia no atendió estas alegaciones, pero terminó desestimando la demanda al considerar probado que el Sr. Czarnecki y su primera mujer, la causante de la actora, se divorciaron años antes de que aquél contrajese nuevas nupcias con la demandada, de modo que no concurría el impedimento de vínculo que determinaría la nulidad que se instaba en la demanda.

La demandante apeló la sentencia de instancia, y el tribunal de apelación de Varsovia, al controlar de oficio su competencia internacional, resolvió formular tres cuestiones prejudiciales al TJUE. La primera y la segunda se refieren al ámbito de aplicación del Reglamento 2210/2003, y la tercera a la interpretación del foro de competencia esgrimido por la actora y aceptado por el tribunal de instancia. Las tres cuestiones son resueltas por la Sala Segunda del TJUE en Sentencia de 13 de octubre de 2016.

\section{Breve contextualización. transnacionalidad y derecho de familia y sucesiones}

3. Tiene algo de atrevimiento tratar de pintar en algunos trazos rápidos el paisaje o contexto sobre el que se proyecta la decisión del TJUE que se comenta. Pero, sin embargo, para valorar las implicaciones y el acierto o desacierto de cualquier resolución recaída en este ámbito, es imprescindible separarse un poco de la norma concreta que se interpreta y aplica y observar esa norma como lo que es, una pieza en un conjunto complejo; conjunto que se encuentra, además, en un momento importante de su evolución.

4. Mientras Europa (en sus diversas construcciones jurídicas) fue concebida como un espacio para la libre circulación de bienes y servicios, el Derecho de familia podía permanecer completamente al margen de las normas europeas, bien resguardado en el ordenamiento interno de cada Estado. Cuando comienza a hacerse evidente que los bienes y servicios no circulan solos, y se va configurando además una sensibilidad política y social en la que gana protagonismo la concepción de Europa como un espacio de circulación de personas, resulta imprescindible atender, por un lado, a que las personas se mueven acompañadas de sus familias -física o jurídicamente, de su situación familiar- $y$, por otro, a que este

\footnotetext{
${ }^{1}$ STJUE de 13 de octubre de 2016, ECLI:EU:C:2016:772. Asunto C-249/15, Mikolajczyk.
} 
movimiento de personas genera la constitución de nuevas relaciones personales y familiares de carácter transnacional.

5. Durante algún tiempo, el único instrumento normativo directamente vinculado con esta realidad es el Reglamento 1347/2000, de 29 de mayo, que establece normas que regulan la competencia, el reconocimiento y la ejecución de resoluciones judiciales en materia matrimonial y de responsabilidad parental sobre los hijos comunes, dictadas con ocasión de acciones judiciales en materia matrimonial, que fue derogado y sustituido por el Reglamento 2201/2003, de 27 de noviembre, relativo a la competencia, el reconocimiento y la ejecución de resoluciones judiciales en materia matrimonial y de responsabilidad parental ${ }^{2}$. Hasta 2009 no se adopta una nueva norma en este ámbito, relativa a la competencia, reconocimiento y ejecución de decisiones en materia de alimentos ${ }^{3}$. En 2010 llega la primera regulación sobre ley aplicable, referida al divorcio y a la separación judicial ${ }^{4}$; y en 2012 la primera norma europea sobre sucesiones, primera también que aúna las dimensiones procesal-competencia, reconocimiento, ejecución- y sustantiva -ley aplicable $-{ }^{5}$. Los últimos eslabones de esta cadena los constituyen por el momento los dos Reglamentos aprobados en 2016 relativos a las cuestiones procesales y sustantivas atinentes a los regímenes económicos matrimoniales y a los efectos patrimoniales de uniones registradas ${ }^{6}$.

6. En todo este corpus, la nulidad matrimonial tiene una situación particular. El Reglamento 2201/2003 incluye en su ámbito de aplicación los procesos de nulidad matrimonial tanto como los de divorcio y separación, de manera que cuando ante los tribunales de un Estado miembro se suscite un proceso de nulidad matrimonial, éstos fijarán su competencia internacional conforme a sus previsiones; y así sucede igualmente con el Reglamento 2016/1103, que regula la atribución de competencia internacional para conocer de cualquier liquidación del régimen económico matrimonial, también de la que se deriva de la declaración de nulidad del matrimonio. Sin embargo, la nulidad del matrimonio está excluida del ámbito de aplicación del Reglamento 1259/2010, de manera que la ley aplicable a la nulidad matrimonial se determina en cada Estado miembro por sus normas internas de Derecho Internacional Privado y no por una norma común. Por si el panorama fuese poco complicado, hay que tener en cuenta además que es frecuente que -a causa de la tradición del Derecho Internacional Privado en estas materias- las legislaciones de los Estados miembros no se remitan a una única lex matrimonii, de manera que la ley sustantiva aplicable a la nulidad de un matrimonio concreto no es una sola, porque tampoco es una sola la que rige la validez del matrimonio, sino que los distintos aspectos que lo configuran como válido (y cuya falta de concurrencia determina la nulidad) están regidos por legislaciones distintas. Toda esta complejidad es determinante para entender y valorar las decisiones adoptadas por el TJUE.

7. Un sencillo ejemplo bastará para comprobarlo. Si se suscita ante los tribunales españoles un proceso de nulidad para el cual son competentes conforme al Reglamento 2201/2003, tendrán que acudir a la norma de conflicto interna para saber conforme a qué legislación sustantiva va a resolverse sobre la nulidad solicitada. El artículo $107 \mathrm{CC}$ dispone que "la nulidad del matrimonio y sus efectos se

\footnotetext{
${ }^{2}$ Como se desprende de los Considerandos 3 a 6 del Reglamento 2201/2003, el Reglamento 1347/2000 no es derogado y sustituido porque se revisen los foros previstos para los procesos matrimoniales, sino para introducir la regulación de la ejecución de resoluciones relativas al régimen de visitas de los hijos.

${ }^{3}$ Reglamento 4/2009, de 18 de diciembre de 2008, relativo a la competencia, la ley aplicable, el reconocimiento y la ejecución de las resoluciones y la cooperación en materia de obligaciones de alimentos.

${ }^{4}$ Reglamento 1259/2010, de 20 de diciembre de 2010, por el que se establece una cooperación reforzada en el ámbito de la ley aplicable al divorcio y a la separación judicial. Como su propio nombre indica, no es un Reglamento aplicable a todos los Estados miembros, sino solo a los que constituyen la cooperación reforzada que regulan los artículos 326 a 334 TFUE.

${ }^{5}$ Reglamento 650/2012, de 4 de julio, relativo a la competencia, la ley aplicable, el reconocimiento y la ejecución de las resoluciones, a la aceptación y la ejecución de los documentos públicos en materia de sucesiones mortis causa y a la creación de un certificado sucesorio europeo.

${ }^{6}$ Respectivamente, Reglamento 2016/1103, de 24 de junio, por el que se establece una cooperación reforzada en el ámbito de la competencia, la ley aplicable, el reconocimiento y la ejecución de resoluciones en materia de regímenes económicos matrimoniales; y Reglamento 2016/1104, de 24 de junio, por el que se establece una cooperación reforzada en el ámbito de la competencia, la ley aplicable, el reconocimiento y la ejecución de resoluciones en materia de efectos patrimoniales de las uniones registradas.
} 
determinarán conforme a la ley aplicable a su celebración". Puesto que la ley aplicable a la celebración del matrimonio no es una sola, habrá que acudir a la que resulte regir el aspecto del matrimonio que esté en cuestión. Si la causa esgrimida es, pongamos por caso, la falta de edad de los contrayentes, habrá que tener en cuenta que, según el artículo 9.1 CC, "la ley personal correspondiente a las personas físicas es la determinada por su nacionalidad. Dicha ley regirá la capacidad y el estado civil, los derechos y deberes de familia y la sucesión por causa de muerte". De esto resulta que la determinación de si cada uno de los cónyuges tenía o no la edad suficiente para contraer matrimonio no se desprenderá de la aplicación de la ley española, sino de la ley de la nacionalidad de cada uno de ellos. En cambio, si la acción de nulidad se funda en una circunstancia relativa a la forma de celebración del matrimonio, el tribunal español tendrá que tener en cuenta los artículos 49 y $50 \mathrm{CC}$, que regulan la ley aplicable a la forma en que el matrimonio se contrae en función de diversos foros, como la nacionalidad de los contrayentes o el lugar de celebración del matrimonio.

\section{Cuestiones prejudiciales relativas al ámbito de aplicación del reglamento 2201/2003}

8. Las dos primeras cuestiones dirigidas al TJUE y resueltas en la sentencia de 13 de octubre de 2016 se dirigen a verificar si el Reglamento 2201/2003 se extiende a procesos de nulidad iniciados tras el fallecimiento de alguno de los cónyuges y si abarca también los procesos de nulidad que insta un tercero distinto de los cónyuges. El TJUE las examina de manera conjunta y mediante dos criterios de interpretación diferentes.

9. El primero de estos criterios es el literal, y, conforme a él, el Tribunal considera que no existe ningún elemento que limite los procesos de nulidad que están integrados en el ámbito de aplicación del Reglamento. No existe en el artículo 1.1 a), que delimita en sentido positivo las materias a las que se aplica el Reglamento y que se refiere a la nulidad matrimonial sin hacer ninguna distinción; y tampoco existe en el artículo 1.3, que enumera en un catálogo cerrado las cuestiones excluidas de su ámbito de aplicación.

10. En segundo lugar, el TJUE se plantea la cuestión atendiendo a un criterio teleológico, a la finalidad de la norma. Y, mirado el asunto desde esta perspectiva, el TJUE concluye que en nada mejoraría la consecución de los objetivos que se persiguen con el Reglamento 2201/2003 y que, en cambio, se vería perjudicada de manera importante la seguridad jurídica, si se considerase que los procesos de nulidad instados tras el fallecimiento de uno de los cónyuges o por un tercero distinto de los cónyuges no forman parte del ámbito de aplicación del Reglamento 2201/2003. Lo que sucedería entonces es que estas situaciones no se encontrarían cubiertas por ninguna norma europea, de manera que se resolverían conforme al Derecho interno de cada Estado miembro, creando un escenario fragmentario y poco previsible, que es precisamente lo que el Reglamento pretende evitar -y lo que, como se ha visto, sucede actualmente con la ley aplicable a la nulidad matrimonial-.

11. A mi juicio, la decisión del Tribunal es acertada. Sin embargo, creo que su fundamentación obvia la razón última de ambas soluciones, que radica, estimo, en las particularidades de la pretensión de nulidad.

La nulidad no es cualquier forma de disolver un matrimonio, sino la pretensión de que se declare que éste nunca existió, que no llegó a contraerse. A diferencia del divorcio, que tiene carácter constitutivo porque extingue una situación jurídica existente y anterior, la nulidad implica la declaración de que la situación jurídica de matrimonio es simplemente una apariencia que en realidad nunca se constituyó jurídicamente, a causa de un vicio concurrente en su origen. Como consecuencia de las diferencias entre la naturaleza jurídica del divorcio y la de la nulidad, la resolución judicial de divorcio -o de separaciónproduce efectos ex nunc, desde el momento en que una situación jurídica nueva sustituye a la anterior; sin embargo, la resolución judicial de nulidad produce efectos ex tunc, que determinan la posibilidad de deshacer lo que se creó, constituyó y fundó en una situación jurídica que no era real, solo aparente. 
12. Si no se atiende a esta diferencia, tiene pleno sentido formularse la primera cuestión prejudicial. El ámbito de aplicación del Reglamento 2201/2003 incluye diversos medios para deshacer un matrimonio, pero excluye todas las cuestiones vinculadas a esa disolución que no son estrictamente la situación jurídica matrimonial -liquidación del régimen económico o sucesión, por ejemplo-. ¿Por qué va a aplicarse entonces el Reglamento a una pretensión que no tiene como objetivo la disolución del matrimonio, puesto que éste ya está disuelto por la muerte de uno de los cónyuges? La razón es que la nulidad no deshace el matrimonio, sino que declara que éste nunca existió: quien insta la nulidad no alcanza solo la modificación de una situación jurídica a partir de la sentencia de nulidad, sino que accede a la posibilidad de poner en cuestión situaciones y relaciones jurídicas que se constituyeron sobre la base de una que no existía, el matrimonio. Dicho de otro modo, la muerte de uno de los cónyuges puede tener en cuanto al matrimonio una eficacia jurídica similar al divorcio, puesto que pone fin a la existencia de una relación conyugal; pero no alcanza a los efectos de la nulidad, que no está relacionada con el final del matrimonio sino con su origen o comienzo, determinando que su eficacia se remonte hasta éste.

13. Es cierto que la nulidad se pretende en este caso, no para que repercuta sobre la relación matrimonial, sino con una intención distinta, probablemente de carácter patrimonial y vinculada a cuestiones sucesorias. Pero los objetivos o motivaciones últimos del actor no afectan al objeto del proceso porque el actor no los incluye en él, sino que se limita a pedir lo único que permite el cauce procesal, la declaración de nulidad del matrimonio. Declaración sin la que, por cierto, no es posible tampoco que el actor articule en otros procesos esas pretensiones, tal vez legítimas. Declara el TJUE que no hay razones literales ni teleológicas - miradas éstas desde los objetivos del Reglamento 2201/2003- para excluir los procesos de nulidad de su ámbito de aplicación aunque uno de los cónyuges haya fallecido. Y es completamente cierto. Pero considero que hay además una tercera razón, igualmente teleológica pero mirada respecto de la institución de la nulidad matrimonial; y consiste en que, en todo caso -es decir, estén vivos o no los cónyuges-, y a causa de su propia y específica naturaleza jurídica, la eficacia de la declaración de nulidad se retrotrae hasta el momento inmediatamente anterior a la celebración del matrimonio, de modo que no tiene sentido distinguir entre cónyuges fallecidos y no fallecidos respecto de una institución jurídica que no está temporalmente limitada por el hecho de la muerte de los cónyuges.

14. La segunda cuestión prejudicial puede observarse desde la misma perspectiva: ¿tiene sentido incluir en el ámbito de aplicación de un Reglamento en el que todo está hecho a medida de los cónyuges, uno en la posición de actor y otro en la de demandado, litigios instados por un tercero, que descolocan el esquema procesal y con él otros aspectos, como la interpretación de los foros de competencia a la que se refiere la tercera cuestión prejudicial? Si se atiende a la naturaleza jurídica de la nulidad la respuesta solo puede ser positiva, puesto que la eficacia de su declaración va a ser la misma independientemente del sujeto que la pretenda, y puede tener una repercusión más amplia que la que alcanza a las esferas personal y familiar de los cónyuges respecto de cuyo matrimonio se pide la declaración de nulidad. De nuevo, no parece adecuado que se distinga entre procesos que tienen la misma eficacia, las mismas consecuencias, solo en virtud de quien ejercita la acción. Además de que, por supuesto, nada hay en la definición del ámbito de aplicación ni en la determinación de las exclusiones de este ámbito que permita considerar que el legislador tuvo la voluntad de excluir del Reglamento 2201/2003 los procesos de nulidad instados por un tercero.

15. Ni los tribunales polacos que intervienen en las dos instancias ni el TJUE se plantean en ningún momento la admisión de la legitimación del tercero, probablemente porque nadie la cuestionaría en el proceso del que traen causa las cuestiones prejudiciales, pero es una materia tan interesante y particular que justifica un momento de atención. Ya se dijo en el epígrafe anterior que la posición de la nulidad matrimonial en las normas europeas de Derecho de familia es discontinua, puesto que algunas la excluyen de su ámbito de aplicación y otras la incluyen. La realidad es que la nulidad matrimonial no es una institución uniformemente extendida en la UE -hay Estados que no la contemplan- ni tampoco uniformemente regulada en los ordenamientos jurídicos de los Estados que sí la albergan. Uno de los puntos en los que existen diferencias notables es precisamente éste, el relativo a la legitimación de sujetos dis- 
tintos de los cónyuges para instar la nulidad de un matrimonio. Téngase además en cuenta, por último, que es posible que los ordenamientos que legitiman a un tercero tampoco lo hagan de manera uniforme ni para todos los casos. Así sucede con el nuestro: hay causas de nulidad alegables por cualquiera sobre la base del artículo $74 \mathrm{CC}$, algunas para cuya alegación se faculta solo a unos cuantos sujetos (la minoría de edad, por ejemplo, artículo $75 \mathrm{CC}$ ), y otras para las que se excluye cualquier legitimación distinta de la de los cónyuges (miedo, coacción o error, artículo 76 CC).

16. La legitimación tiene una vertiente procesal y otra vinculada a la relación sustantiva que constituye el objeto del proceso. Lo expresa muy bien el primer inciso del artículo 10 LEC: "Serán considerados partes legítimas quienes comparezcan y actúen en juicio como titulares de la relación jurídica u objeto litigioso". Para comprobar, por tanto, si la legitimación que un sujeto alega tener está amparada por el ordenamiento jurídico, hay que acudir a la legislación aplicable para resolver el fondo del asunto. Y, como se ha dicho ya, ni existe una norma europea para determinar la legislación aplicable a la nulidad matrimonial, excluida del ámbito del Reglamento 1259/2010, ni existe, en el caso de nuestro Derecho interno, una única ley aplicable al régimen jurídico completo del matrimonio. Como consecuencia, si el proceso de nulidad se suscitase por un tercero distinto de los cónyuges ante los tribunales españoles, y éstos se estimasen competentes para conocer en virtud del Reglamento 2201/2003, escogerían como ley aplicable a la nulidad la que regulase la validez del aspecto que se alega como causa de nulidad: la ley personal de cada cónyuge si la petición de nulidad se funda en la falta de capacidad, de consentimiento o en la existencia de un impedimento de ligamen (artículo 9.1 CC), o la ley del foro de nacionalidad o de lugar de celebración conforme al que se hayan ordenado los aspectos formales del matrimonio (artículos 49 y $50 \mathrm{CC}$ ), por poner algunos ejemplos. Dos observaciones breves son aún necesarias para cerrar esta cuestión:

- La primera es que pongo los ejemplos de ley aplicable que me parecen indiscutibles. Pero hay un grupo importante de supuestos -que no desarrollaré aquí, porque se aleja mucho del objeto de este comentario- que podrían subsumirse en más de un apartado del artículo 9 CC, o en ninguno, como por ejemplo el error sobre la identidad o condiciones del otro contrayente, o sobre las cargas y obligaciones derivadas del matrimonio.

- A mi juicio, y puesto que no existe ley general sobre la validez o invalidez del matrimonio, la legitimación de un tercero para instar la nulidad solo puede regirse por la ley que a su vez rija la circunstancia del matrimonio en la que el tercero funde la causa de nulidad que alega. Esta interpretación, que es muy poco satisfactoria por su fragmentación y por la inseguridad jurídica que origina, tiene al menos dos ventajas. La primera, seguir el mismo criterio de determinación de la ley aplicable que se utiliza para los restantes aspectos relativos a la nulidad del matrimonio - que también resulta increíblemente fragmentario e inseguro, atendidos el grado de evolución jurídica que tenemos y la importancia y volumen de este tipo de litigios-. La segunda consiste en que permite adaptarse a ordenamientos como el nuestro que, reconociendo legitimación a terceros para instar la nulidad del matrimonio, no la otorga en igual grado ni a los mismos sujetos respecto de todas las causas de nulidad y en todas las circunstancias?

\footnotetext{
${ }^{7}$ Dentro de la inseguridad propia de este ámbito, no comparto, por ejemplo, la solución dada por la SAP Madrid 363/2014, de 4 de abril, a un supuesto en el que el hijo de la esposa fallecida, española, demanda al cónyuge supérstite, cubano, instando la nulidad del matrimonio celebrado en Cuba por falta de consentimiento de su madre a causa de una disminución de sus facultades mentales. La APr de Madrid entiende aplicable la norma de conflicto prevista en el artículo 9.2 CC para los efectos del matrimonio (no comprendo por qué, puesto que los efectos del matrimonio están constituidos por los personales propios del vínculo jurídico matrimonial y por los patrimoniales que se concretan en el régimen económico matrimonial), y dentro de los foros de competencia establecidos por ella, el del lugar de celebración del matrimonio, Cuba. Considera que ésta es la legislación aplicable a las causas de nulidad y a la legitimación para solicitarla, y desestima la demanda porque la legislación cubana solo legitima a los cónyuges y al Ministerio Fiscal para instar la nulidad de un matrimonio. Por mi parte, considero que nada indica que la ley aplicable a los efectos del matrimonio sea la que debe regir la nulidad matrimonial en conjunto, sino, muy al contrario y como se ha explicado, que todo parece concluir que no hay una norma de conflicto única sino una previsión específica de ley aplicable para cada circunstancia determinante de la validez del matrimonio. De manera que, a mi juicio, si el demandante pretendía la nulidad con fundamento en la falta de capacidad de su madre para prestar consentimiento, la APr debería haber aplicado la legislación que rige la capacidad, que es la nacional de cada contrayente (artículo 9.1 CC), y, en este caso concreto, la española. La legislación española será la que resuelva si la mujer tenía o no la capacidad exigida-también por la ley española, ley personal
} 


\section{Cuestión prejudicial relativa al foro de competencia para conocer del proceso de nulidad insta- do por un tercero}

17. La tercera cuestión prejudicial se refiere a la interpretación del foro de competencia alegado por la actora para fundar la jurisdicción de los tribunales polacos. El artículo 3 del Reglamento 2201/2003 prevé un conjunto de foros para la atribución de competencia que funcionan de manera alternativa y no jerárquica; de esta alternatividad resulta que es posible que sean competentes para conocer de un asunto concreto los tribunales de más de un Estado miembro, asumiéndolo aquél de entre ellos ante el que ha sido formulada la demanda. El texto literal de la norma es el siguiente:

“1. En los asuntos relativos al divorcio, la separación judicial y la nulidad matrimonial, la competencia recaerá en los órganos jurisdiccionales del Estado miembro:

a) en cuyo territorio se encuentre:

- la residencia habitual de los cónyuges, o

- el último lugar de residencia habitual de los cónyuges, siempre que uno de ellos aún resida allí, o

- la residencia habitual del demandado, o

- en caso de demanda conjunta, la residencia habitual de uno de los cónyuges, o

- la residencia habitual del demandante si ha residido allí durante al menos un año inmediatamente antes de la presentación de la demanda, o

- la residencia habitual del demandante en caso de que haya residido allí al menos los seis meses inmediatamente anteriores a la presentación de la demanda y de que sea nacional del Estado miembro en cuestión o, en el caso del Reino Unido e Irlanda, tenga allí su "domicile";

b) de la nacionalidad de ambos cónyuges o, en el caso del Reino Unido y de Irlanda, del "domicile" común.

2. A efectos del presente Reglamento, el término "domicile" se entenderá en el mismo sentido que tiene dicho término con arreglo a los ordenamientos jurídicos del Reino Unido y de Irlanda".

18. Como puede verse, los foros comprendidos en la letra a) giran en torno a la residencia habitual, mientras que el previsto en la letra b) se funda en la nacionalidad. Pero, así como no ha lugar a preguntarse a qué sujetos se refiere la nacionalidad que funda la competencia, porque la norma menciona expresa y únicamente a ambos cónyuges, el apartado a), que contiene foros ligados a la residencia habitual, vincula ésta con sujetos distintos: los cónyuges (guiones primero, segundo y cuarto), el demandado (guion tercero) y el demandante (guiones quinto y sexto).

19. La Sra. Mikolajczyk, demandante, insta la nulidad del matrimonio de su causante ante los tribunales de su propio domicilio, al amparo de lo prevenido en el guion quinto de la letra a) del artículo 3.1 del Reglamento 2201/2003. Y el tribunal de apelación de Varsovia eleva al TJUE la cuestión de si puede entenderse por "demandante", a efectos de fundar la competencia del tribunal en las normas del Reglamento 2201/2003 a un sujeto distinto de los cónyuges.

20. El TJUE ofrece una respuesta sencilla y aparentemente razonable, sensata y sin aristas: las normas de competencia del Reglamento 2201/2003 "tienen como objetivo preservar los intereses de los cónyuges" (fundamento 49), de modo que el tercero que puede demandar amparado por el ámbito de

de la contrayente, porque no hay una ley común que establezca los requisitos para contraer matrimonio-, e igualmente la que determine si esa falta de capacidad puede ser esgrimida por un tercero para obtener la nulidad de la declaración del matrimonio. La solución del supuesto concreto habría sido completamente distinta, puesto que conforme a los artículos 73 y siguientes CC el actor sí estaría legitimado para ejercitar la acción de nulidad por esta causa, de modo que el tribunal habría tenido que entrar en el fondo del asunto y resolver sobre la capacidad o no de la contrayente para prestar consentimiento. 
aplicación del Reglamento queda "sometido a las normas de competencia definidas en interés de los cónyuges" (fundamento 51), concluyendo como consecuencia que el concepto de demandante que aparece en el artículo 3.1 a) del Reglamento "no incluye a personas distintas de los cónyuges" (fundamento 52). Sin embargo, y sin cuestionar absolutamente la decisión del TJUE, sí considero que hay extremos, aspectos, que disuenan, con la institución de la nulidad matrimonial, con el propio Reglamento 2201/2003 y con el conjunto de normas europeas sobre Derecho de familia que se han promulgado tras el Reglamento 2001/2003. Los puntos en los que algo "roza" pueden sintetizarse en los que a continuación se exponen.

21. La primera de estas disonancias, aunque no tenga mucha importancia, se produce en el interior de la propia resolución judicial. Mientras que la respuesta a las cuestiones primera y segunda se apoya (no solo, pero sí en primer lugar) en una interpretación literal estricta, consistente en no decir lo que el Reglamento no dice, la respuesta a la cuestión tercera se funda exactamente en lo contrario, en entender que la norma dice "cónyuge demandante" en lugar de "demandante". No es una observación que tenga mucho más recorrido, aunque es cierto que la propia norma usa la condición "cónyuge" para definir otros foros de competencia y no los que se contienen en los guiones quinto y sexto del artículo 3.1 a), y que, a su vez, "demandante" y lo que este concepto implica no es algo novedoso para el legislador europeo, sino una condición profusamente manejada para definir criterios de competencia ${ }^{8}$.

22. Más chocante es la confrontación del interés de los cónyuges como criterio de interpretación con la naturaleza de la acción de nulidad. La nulidad matrimonial como institución jurídica no se dirige fundamentalmente a proteger el interés de los cónyuges, sino el del ordenamiento jurídico en su conjunto y la configuración de la realidad social sobre la que se proyecta. Precisamente porque la nulidad no tiene como objeto la protección del interés de los cónyuges hay sujetos distintos de ellos legitimados para instarla: el Ministerio Fiscal en representación del interés público, y terceros titulares de derechos o situaciones jurídicas que determinen la concurrencia de un interés legítimo en la declaración de la nulidad del matrimonio. Si el criterio rector de la institución jurídica de la nulidad matrimonial no es el interés de los cónyuges, tampoco tendría que ser necesariamente -como parece desprenderse de la STJUE- el elemento central de los foros de competencia destinados a que se declare.

23. Pero es que tampoco resulta ser exactamente cierto que el centro de los foros de competencia del Reglamento 2201/2003 se sitúe en el interés de los cónyuges. Si acaso, de alguno de los cónyuges, del cónyuge demandante, que es distinto. Si el sistema de determinación de la competencia en materia matrimonial primase el interés de los cónyuges, contemplaría la posibilidad de pacto entre ellos para seleccionar el tribunal competente, o al menos la sumisión tácita, como ocurre, por ejemplo, en los Reglamentos relativos a la sucesión o al régimen económico matrimonial en las condiciones por ellos previstas. Es cierto que en los últimos diez años el Derecho de familia, a nivel europeo, ha experimentado una fuerte evolución que lo va conduciendo del ámbito del interés público y de la indisponibilidad a unos parámetros en los que se presta mayor atención a los derechos e intereses individuales de los implicados, a una esfera más privada y disponible. El Reglamento 2201/2003, con sus foros alternativos que permiten -y provocan- la conocida como "carrera hacia los tribunales" -para resultar el actor y no el demandado, y ser quien elija, en consecuencia, entre los distintos foros posibles, el más adecuado a los propios intereses-; con la indisponibilidad total de sus normas y con la rigidez de sus criterios

\footnotetext{
8 También hay alguna pequeña contradicción entre la sentencia Mikolajczyk (ECLI:EU:C:2016:772 y la de 16 de julio de 2009, ECLI:EU:C:2009:474, mediante la que el TJUE resuelve el asunto C-168/08, Hadadi. La sentencia que comentamos cita esta otra en su apoyo, en el fundamento 47. Sin embargo, estimo que el pronunciamiento del asunto Hadadi al que se hace referencia en este fundamento se realiza de pasada, y no para determinar si todos los foros de residencia habitual están vinculados a los cónyuges sino para resaltar la diferencia entre los puntos de conexión que se vinculan a la residencia habitual y los que se sostienen sobre la nacionalidad, que son - estos últimos- el objeto de las cuestiones prejudiciales que en ella se resuelven. En cambio, mientras que en la sentencia Mikolajczyk el fundamento 51 afirma que la interpretación que limita la competencia del Estado de residencia habitual del demandante a que éste sea uno de los cónyuges no priva a los terceros del acceso a la justicia, porque cuentan con los otros foros previstos en el Reglamento, el fundamento 53 de la sentencia Hadadi rechaza la interpretación propuesta por una de las partes porque entiende inadecuado "restringir la facultad de los justiciables de elegir el tribunal competente, concretamente en el supuesto de ejercicio del derecho a la libre circulación de las personas".
} 
se ha quedado obsoleto. Es comprensible y necesario que la interpretación del TJUE lo actualice y lo armonice con el resto de las normas que integran el sistema jurídico al que pertenece. Pero el resultado de esta tarea no debe redundar en perjuicio de un sujeto que, respecto de la acción que ejercita, está tan legitimado como los cónyuges conjuntamente, y como cualquiera de ellos por separado. No tiene una explicación sencilla la razón que permite favorecer al cónyuge demandante pero no al tercero que demanda con la misma legitimación que él. La fragilidad de este criterio del interés de los cónyuges, su apariencia de destilado a posteriori y orillando la literalidad de la norma, resalta con crudeza en el contraste con el interés superior del menor, formulado como un prius por el legislador en los Considerandos 12 y 13 del Reglamento, como criterio del que emanan y que rige los foros de competencia en materia de responsabilidad parental.

24. Desde luego, si el tercero que insta la nulidad de un matrimonio pudiera hacerlo ante los tribunales del Estado en el que ha tenido su residencia habitual durante el año anterior a la interposición de la demanda, se correría el riesgo de que los cónyuges se encontrasen ante un foro exorbitante, ante los tribunales de un Estado que no tiene ningún punto de conexión con la relación conyugal cuya nulidad se pretende. Sin embargo, este mismo efecto, convenimos que indeseable, puede ser sufrido por cualquiera de los cónyuges ante la demanda de nulidad, separación o divorcio formulada por el otro cónyuge con amparo en el mismo criterio de competencia. No parece muy razonable que el foro exorbitante sea tolerado cuando beneficia a un cónyuge pero proscrito cuando beneficia a un tercero que, no lo olvidemos, tiene la misma legitimación que los cónyuges respecto de la acción que ejercita. Al mismo punto de razonamiento se llega si, en lugar de mirar la decisión del TJUE desde la perspectiva del foro exorbitante, se contempla desde la óptica de la previsibilidad, otro factor valioso que los Reglamentos de atribución de competencia internacional tienden a salvaguardar. Es cierto que la posibilidad de que un tercero inste la nulidad de un matrimonio ante los tribunales de su residencia habitual abre extraordinariamente el abanico de los Estados ante los que puede suscitarse un proceso respecto de un matrimonio concreto. Pero resulta igualmente cierto que la previsibilidad no es el valor fundamental de una norma que contiene foros alternativos y que no excluye la concurrencia de competencias. Además de que, de nuevo, es igualmente poco previsible el Estado en el que uno de los cónyuges puede fijar su residencia habitual tras la ruptura de la convivencia, convirtiéndolo así en foro propicio para instar un año después la separación, la nulidad o el divorcio. Los foros de competencia previsibles están vinculados al pasado; lo que se abre al futuro excede de lo que los hombres podemos prever. 